\title{
Curriculum Development Strategy of Adult Education under the Theory of Modern Adult Education Development
}

\author{
Hua Wang \\ Nanjing University \\ Nanjing, China 210000 \\ Taizhou University \\ Taizhou, China 225300
}

\begin{abstract}
With the development of the times and the concept of lifelong learning, adult education has become an important part of the development of higher education in China. And it also has played an active role in improving the quality of personnel training. The theory of adult education development has pointed out the direction for the development of adult education in China. And it has provided good guarantee for the reform and progress of adult education. From the present situation of the development of adult education curriculum in China, there are still many practical problems in the development of adult education curriculum, which points out the insufficiency of adult education in China. Therefore, in order to improve the teaching level of adult education, it is necessary to develop a targeted curriculum development strategy under the modern adult education development theory. And then, it can promote the development of adult education.
\end{abstract}

Keywords-modern adult education; theory of development; curriculum development

\section{INTRODUCTION}

With the accelerated pace of the construction of learningoriented society and the idea of lifelong learning in China, the continuous study has become an important goal of the development of the society in China. And it is also an important requirement for society. For a long time, the development of adult education in China is relatively slow. And in the development process, it often has a variety of problems. And it is mainly due to the deficiency of the theory of adult education in China. And the relevant systems aren't comprehensive enough. In recent years, with the continuous progress of science and technology in China, the theory of adult education development has been constantly improved with the development of the times. The theory of modern adult education development has become an important guiding principle for adult education in China. And it has made great progress in promoting social

Project Fund: This paper is supported by the Qing-lan project of the colleges and universities, cultivation of outstanding young backbone teachers, department of education in Jiangsu provincial in 2017. And it is also supported by the fund of the construction of bilingual curriculum in Taizhou University. development in China. Therefore, the curriculum development of adult education has become an important issue for the society in China. The government and related agencies must develop appropriate strategies to improve the quality of adult education teaching, and to enhance the teaching level of adult education. And it can cultivate a large number of advanced talents for the development and progress of Chinese society [1].

\section{THE OVERVIEW OF THE THEORY OF MODERN ADULT EDUCATION DEVELOPMENT}

The theory of modern adult education development has been improved on the basis of the traditional theory of adult education. In the theory of modern adult education development, the adult learners are deeply analyzed from the aspects of the characteristics of adult learning, the learning ability of adult learners and the learning motive of adult learners. And it has fully grasped the learning characteristics, psychological characteristics and behavioral characteristics of adult learners. It has provided good supports and protection for the construction of adult education curriculum system and curriculum development. At the same time, according to the characteristics of the times and the development trend of China's social education, it has made new instructions. And it also has developed clear development policy. Also, it has made great contribution for the development of adult education in China.

Compared with the students in the colleges and universities, the physical function and the ability of memory are quite different. Normally, the learning ability of adult learners will not decline or terminate with their age and physiological maturity. It is the best time for adult learners to develop learning activities about 30 years old. About the 50 years old, the learning ability of adult learners will gradually decline. However, the decline trend is not dramatic. Secondly, intellectual activities as the effective means of adult learners to delay the mental decline have played important role in adult education. After the age of 37 years old, the level of memory of adult learners has begun to decrease. On the contrary, logical thinking, critical thinking 
and understanding have gradually increased. Therefore, adult learners still have certain advantages in adult education.

Compared with the ordinary full-time students, adult learners also have many unique characteristics in the learning process. First of all, physiology and psychology of adults have been mature. It has accumulated a wealth of learning experience and life experience in the work. However, due to the burden of the family and the burden of work, adult learners need the continuous learning and continuous progress. And then, they can improve their income level to meet their needs. Therefore, to have the adult education has become an important way for many adult learners to upgrade themselves. However, in terms of continuing education, such life experience for adult learners has both beneficial and adverse effects. For example, the existing knowledge structure of adult learners can effectively stimulate their learning motivation, and enhance the acceptance of knowledge. And it can make the activities of adult education develop in an orderly manner. However, these existing experiences would make adult learners form a fixed mind. And it may affect its growth and development in adult education. Secondly, most of adult learners are self-directed and self-control. Adult learners' outlook on life, values and the concepts of development have been formed. With the formation of independent personality, they can make selfanalysis in the learning process. At the same time, adult learners rely less on teachers. According to their actual needs, they can develop appropriate learning plans or goals. Also, they can find the appropriate learning resources. Finally, in the process of adult education, the contradiction between the work and learning is very common for adult learners. To a certain extent, this contradiction will affect the learning quality and learning effect of adult learners. In the adulthood, the ways of life and thinking will have certain changes. For these adult learners, learning is no longer the only living content. They also have to bear a variety of responsibilities and obligations. They should not only complete their learning tasks, but also should complete their work. Also, they must play their social roles and family roles. The scholar, Horace believes that once the adult learners learning activities are in conflict with their works. The adult learners often return to their posts. And they will temporarily give up learning. Therefore, for adult learners, the serious academic contradictions will directly affect the learning effect of adult learners [2].

\section{The PRESENT SituATION AND PROBLEMS OF AdUlt EDUCATION CURRICULUM DEVELOPMENT}

In view of the characteristics of adult learners, teachers and related institutions must develop effective teaching programs and teaching strategies based on learning characteristics, personality characteristics and behavior characteristics of adult learners in the process of adult education. Only in this way, it can meet the needs of adult learners to have continuous learning. In the process of adult education, curriculum development is an important activity. However, viewing from the actual situation, there are many problems in the development of adult education curriculum. The emergence of these problems reflects the deficiency of adult education and teaching system and the lack of supervision. If these problems can't be reasonably resolved, it will directly affect the teaching quality and teaching effects of adult education. Also, it can affect the quality of the development of adult education curriculum. It can be seen that the study on the current situation of the development of adult education curriculum is of great significance for the development strategy of sound adult education curriculum.

\section{A. The Adult Education Curriculum doesn't Match with the Goal of Personnel Training}

In the actual survey, the dislocation development between adult education curriculum and the goal of personnel training is the outstanding problems in the development of adult education curriculum. Most of adult learners have works. So their needs of learning are often closely related to their works. And then, it makes the adult learners pay more attention to the practicality of the course content and the cultivation of practical skills in the process of adult education. The cultivation of applied talents is the direction of adult education curriculum. Viewing from the current status of adult education, it has opened many courses of adult education. However, the content of these courses mainly focus on the theoretical knowledge and academic knowledge. However, it has made less training in the practical skills. And teachers often copy the teaching content of higher education. The social adaptability of adult learners is difficult to be effectively trained and upgraded. It is difficult to meet the needs of the community on the applied talents. And then, it has caused the lack of talents and the dislocation of personnel training objectives.

\section{B. There Are Fewer People Involved in the Development of Adult Education Curriculum}

From the current teaching status of adult education, the elitism of adult education curriculum is heavy. In the development of adult education curriculum, if it needs to modify the teaching plan, the relevant departments will collect their own teaching plans and the teaching plans of other institutions. And they would make simple addition and subtraction of the course and class time. And some schools will organize the teaching force of each college to develop the adult education and teaching plan according to their own subjective wishes. According to the curriculum content of the teaching plan, it can invite the relevant teachers to develop the syllabus. This course is set according to the chapters of the textbook. It doesn't develop the targeted teaching plan according to the actual needs of adult learners. And it is too rigid. It is difficult to meet the social needs of adult learners. Also, it is difficult to meet the needs of the growth and development of applied talents.

\section{Curriculum Content and Curriculum Structure Aren't Consistent with the Cultivation of Applied Talents}

Through the understanding of adult education in teaching process, it can be found that they can't be fully aware of the characteristics of adult learners, as well as their own existing knowledge structure in many colleges and universities. They still develop the curriculum in accordance with the traditional teaching methods of education. And it has made the repetition in the adult education curriculum and content. In the process of adult education, colleges and universities 
have paid too much attention to theoretical teaching. And they have ignored the importance of skills training. In addition to the above content, the skills training of reemployment for the adult learners is lacking. Then, it has caused the dislocation between theoretical knowledge and skills training. The main reason for these problems is that adult education curriculum and development are the same as those of higher education. The subject center is the core of curriculum development. And any teaching activity is carried out with this center. This course doesn't take full account of the characteristics of adult learning. It has ignored the importance of combination of theory and practice. And if it is separated from the production needs, it can't be able to meet the requirements of adult education development [3].

\section{The Faculty and Teaching Methods can't Meet the Needs of Adult Learners}

As the adult learners have certain theoretical foundation of knowledge. And they have formed the unique thinking mode and learning mode. So the traditional learning mode can't satisfy the learning needs of adult learners. However, from the current situation of adult teaching, the university still adopts the traditional classroom teaching mode in the process of adult education. The learning enthusiasm and motivation of adult learner is low. The learning atmosphere of classroom is relatively low. And it has influenced the teaching quality of adult education. At the same time, it has also affected the work enthusiasm of teachers. In the end, it will affect the reform and development of adult education. Adult learners have their own understanding of things. If teachers impose their own ideas on adult learners, it will arouse the antipathy of adult learners. And adult education workers must take an active part in all kinds of teaching training. They should improve their theoretical level, and update their knowledge structure. And they can be able to respond to questions from the adult learners in the process of learning. They also can response to the adult learners in time. And then, it will not affect the opinions of adult learners on the education. Therefore, it is urgent to raise the theoretical level of adult education workers and improve the overall quality of teachers.

\section{THE STRATEGY ON THE DEVELOPMENT OF ADULT EDUCATION CURRICULUM}

Due to the learning characteristics, work characteristics and thinking characteristics of adult learners, the development of adult education curriculum must make a specific teaching plan based on the actual situation of adult learners. And it should carry out various teaching activities under the guidance of the theory of modern adult education development. If it wants to make more targeted development of adult education curriculum, and improve teaching quality and teaching level of adult education, it must have a thorough understanding of learning characteristics and actual needs of adult learners. And it has formulated the development strategy of curriculum from the following aspects.

\section{A. To Improve the Professional Quality of Adult Education Workers}

As an important driving force for adult education, adult education workers play a crucial role in the development of adult education. As the subject of adult education curriculum development, the professional quality of adult education workers directly affects the development quality and development effect of adult education. In the 21 st century, science and technology have developed particularly rapidly. And the update speed of knowledge has become faster and faster. And the demands for talents have become higher and higher. And it has also raised higher requirements for the comprehensive ability of adult education workers. Therefore, the comprehensive ability of adult educators directly affects the development quality of adult education. The good adult education workers must have good moral cultivation, high professional skills and noble professional culture. And they also must strive to be enterprising. To improve the comprehensive literacy and professional skills of adult education workers, it is necessary to cultivate the lifelong learning and education awareness of adult education workers. Specifically, the relevant training institutions for adult education and the colleges and universities should regularly organize adult education workers to participate in various teaching and training activities. These training activities are not only about teaching content and teaching theory of adult education, but also on the learning characteristics and teaching methods of adult education, etc. If it is necessary, it should organize teachers to foreign adult education colleges to learn. In addition, it should host various lectures regularly. And it should organize experts and scholars from various neighborhoods to carry out academic exchange activities. And it can provide face-to-face communication opportunities for adult education workers. Then, these scholars can answer questions for adult education workers. And it provides theoretical assistance and practical guidance [4].

\section{B. To Construct an Exclusive Mechanism of Supervision and Evaluation for Learning Outcomes of Adult}

In the development of adult education curriculum, the relevant workers will develop the curriculum content suitable for the development needs of the relevant institutions according to the actual development needs of the organization, the teaching resources and the decision of the university leaders. For adult learners, adult education workers need to get better understanding of adult learners' satisfaction with their own actual situation. And they also should understand future development plans, and the relevant theoretical knowledge. And then, it will discover the adult learners' needs. Adult education workers should integrate the learning outcomes of adult learners into the development system of adult education curriculum. And it can improve the curriculum design pattern of adult education. Compared with the western countries, China's adult education started late. And the relevant system is not perfect. Western countries have accumulated a lot of successful experience in the development and design of adult education curriculum. Therefore, in the development of adult education curriculum system, China should actively learn from the successful experience of curriculum development in western 
countries. According to the characteristics of Chinese adult learners and the status of adult education development, it can develop the effective teaching programs and teaching system. Also, it should establish a sound supervision and management mechanism. Then, it should collect and summarize the academic performance and learning outcomes of the adult learners. It can make analysis. Later, it should adhere to the following survey. It must master the learning situation of adult learners comprehensively. And it can improve the teaching system of adult education. Then, it can provide the solid foundation for the improvement of the quality of adult education and the development of adult education.

\section{To Pay Attention to the Design and Research of the Target of Adult Education Curriculum}

According to the theory of modern adult education development and the relevant researches on Taylor's behavioral goal theory, it can find some things. In the development of adult education curriculum, the learning outcomes of adult learners mainly include three concepts: cognition, emotion and motor skills. These theories provide professional guidance and help for the development of adult education. And these theories are conducive to helping adult education workers avoid fuzzy and blind situation in the development of the learning objectives. Adult education workers can correctly and comprehensively recognize the learning characteristics and behavioral characteristics of adult learners. It can provide scientific theoretical support and assistance for the improvement of the overall performance of adult learners. However, these theories make adult education workers ignore the inner demands of adult learners. And they also have ignored the emotional changes of adult learners in the process of teaching. And then, the adult education becomes a mere formality. Therefore, for adult education workers, it must understand the learning characteristics of adult learners. And it should pay attention to the development of adult education curriculum. And then, it can better absorb the successful experience of adult education. According to their actual needs and teaching practice, it can design teaching objectives for the growth and development of adult learners. [5]

\section{To Pay Attention to the Development and Design of Recessive Subject in Adult Education}

In addition to explicit content, recessive subject also has far-reaching impact in the process of adult education. The teaching contents of recessive subject are very rich. It not only includes academic knowledge, but also non-academic knowledge. The acceptance mechanism of invisible content is often unconscious. It has increased the difficulty of the development of recessive subject of adult education. It requires the developers of adult education curriculum to improve self-awareness in the development process of invisible content. And they should actively use the development art of the adult education curriculum. Also, they must strengthen the communication among adult learners, university leaders and government agencies. And they have played an active role in guiding the development of adult learners. And they must help adult learners develop the right development goals and learning goals in education.
Secondly, in the development of adult education curriculum, colleges and universities should understand the real needs of adult learners. On this basis, it can build free and democratic, equal and harmonious teaching environment. Finally, adult education workers should also correctly understand the teaching scope and educational type of recessive subject of adult education. It should develop the teaching content objectively and teaching resources.

\section{E. To Develop Personalized Teaching Content for Adult Education and Adult Learners}

As adult learners have many different learning characteristics. And they may be influenced by the work, family and life. The learning environment and living environment of adult learners is more complex. Therefore, in the development of adult education curriculum, it must fully understand the complexity of adult education activities and teaching objects. It should develop targeted teaching content for the different areas of work, different areas of adult learners. And it also needs to make a difference among these learners. Adult education workers should fully understand the scope of adult education curriculum, understand the practical needs and life needs of adult learners, timely pay attention to psychological changes of adult learners. So, the teaching content of adult education can meet the needs of different adult learners. It can make a good solution to the contradictions between the learning of adult learners and work. And it can maximize the utilization of various teaching resources. It can develop the teaching activities of adult education smoothly [6].

In addition, in the development of adult education curriculum, colleges and universities and related educational institutions should actively use a variety of advanced teaching methods and science and technology to develop new teaching methods. For example, it can use Internet and multimedia technology to develop distance education methods to break the time and space constraints on adult learners. The adult learners can freely choose the learning content anytime and anywhere. Then, it can meet their growth and development needs. It can establish adult education sites and exchange forums. Then, adult learners can find like-minded friends on the website. Also, they can be able to connect with teachers. The adult learners can solve the problems in the learning process timely and effectively. In the end, it can improve the quality of adult education.

\section{CONCLUSION}

It has put forward new requirements for talents with the continuous development and progress of the times. The theory of adult education development has been improved with the progress of the times. In view of the present situation and problems of adult education curriculum development, universities and related institutions should develop effective teaching programs according to the actual needs of adult learners. It should improve the teaching quality of adult education. Also, it should promote the development of adult education and enhance the quality of talents. 


\section{REFERENCES}

[1] Zhang Zhiye. The literature review on the development direction of theoretical research on Chinese adult education [J]. Journal of Beijing Xuan Wu Hong Qi spare-time university, 2016, 02:28-31.

[2] Huang Chunmei. On the development of adult education curriculum with digitization in Guangxi [J]. Higher Education Forum, 2014, 11:120-124.

[3] Yuan Hongying. The enlightenment of theory of multiple intelligence to the development of Chinese adult education curriculum [J]. Contemporary Adult Education, 2015, 02:67-70.

[4] Ling Ling. Research on the development of theory of adult education in America in the early and mid-20th century [J]. Adult Education, 2015, 11:9-13

[5] Liu Saisai. The development of adult education curriculum under the background of lifelong education [J]. Education and Career, 2014, 23:121-122.

[6] Chen Zaiming. Study on the development of adult education curriculum in colleges and universities [J]. Chinese Adult Education, 2013, 04:113-115. 